\title{
Analysis of the situations of Government Leading Fund in China
}

\section{Wen Gao}

\author{
Oxbridge college, Kunming university of science and technology \\ panpanbear@hotmail.com
}

Keywords: Government Leading Fund, Private equity, Government

\begin{abstract}
The first government leading fund in China was setup in 2002, which name is Zhongguangchun Government Leading Fund of Venture Capital. During nearly 15years developed, the Government Leading Fund from a child grows up to a young lady base on a set of convention and rules from government. Now, the Government Leading funs tend to one of important LP in capital market. There is serious competition in PE market who wants to work with Government Leading Fund. The reason is that the Government Leading Fund has some nature advantages in scale and goal of investment. This article wills discuses the situation of Chinese Government Leading Fund. And then propose some suggest about how to jump out of this situation.

Government Leading Fund is established by the government's financial capital. The goal of Government Leading Fund is attracting social capitals, some local government capitals and private equity. The purpose of Government Leading fund is not earning profits. It is use the equity, debt and other methods to invest in venture capital in order to support the business and the development of local economy.
\end{abstract}

\section{The situation of Government Leading Fund in China}

Firstly, the number of Government Leading Fund increases quickly. The first Government Leading Fund was born in 2002. But after 2007's financial crisis, Government Leading Fund accelerate the develop seed. There are parts of provinces and cities began to fund theirs regional Government Leading Fund. According Qingke Group's data, there are 96 Government Leading Fund in China. The capital scale is RMB 700 billion. In 2014, the number of Government leading Fund jump to 209 and control RMB 1293.39 billion. Each Government Leading Fund's scale is over RMB 6.19 billion.

Secondly, the distribution of Government Leading Fund has area difference. There are two hot areas in map of Government leading Fund. They are ChangJiang area and Bohai gulf. Based on Zhongtou Group's CVSource until 2014, there are 90 Government Leading Fund was funded in Huadong district. The target scale is RMB601 billion. It seems to be NO.1 in China. The number of government Leading Fund in southwest and northeast are 18 and 35, and the capital scopes are RMB 248 billion and RMB144.6 billion. The last part of Huanan district, the scale and the number of Government Leading Fund are RMB114.78 billion and 35.

And then, the Healthcare, TMT, clean energy and environmental protection are most three favorite investment fields. Depend on Zhongtou Group's CVSource, these three fields count to 20\%, $19 \%$ and $19 \%$ in all invest projects.

Thirdly, the Government Leading Fund has some special operating requirements. The Government Leading Fund usually requires sub-fund invest in the local by the mount of government investment 50\%-70\%. If invest in early stage of one industry, this kind of investment seem to push the development of corporation in quantity and scope. For example, in Longgang district Shengzhen city's Government Leading Fund of venture capital, the government contributive RMB1.8 billion. But the scale of sub- fund comes to RMB11.80 billion, increasing 6.58 times. It seems to be shown the financial leverage of government capital. 


\section{The problems of Government Leading Fund in China}

The first question is that lack the information disclosure system. As the beginning of government Leading Fund setup stage, the strange broadcasting and concentration attract experienced GP. But after come to operating procedure, the large part of information about the sub-fund was missed. Some Government Leading Fund websites, it is easy to find the number and the scope of Government Leading Fund. But the sub-fund how to quite and how much profits earned. This kind of information did not public on website. Furth more, according some regional rules, it requires the sub-fund should invest 50\%-70\% of the mount of Government Leading Fund. And restricted the invest target should in limited field. However, those information still was lacking.

The second problem is some outstanding GP do not willing to fund in two or three line city. Due to this reason two and three line city allure significant GP. In China, there is huge number of PE and VC established in Beijing, Shanghai, Shenzheng and Guangzhou. Due to this reason, these local Government Leading Fund has mount of outstanding GP can chose and easy to make a agreement. Experienced GP tend to use plentiful project reserves and local recourses to make sure the operation of Government Leading Fund. Ant the meantime, the GP develops backward in two and three line city. There is lacking exporters and outstanding GP group. Some managers of Government Leading Fund come from government. These managers do not familiar with how PE and VC are working. It seems to spent lots of time to research it.

The last problem is that the low efficient of capital using. When Government Leading Fund setup, it required some field should invest and how much percentage should invest in local projects. In first normative document on the establishment and operation about Government Leading Fund demand the fields and the mount of capital should invest. Illustrate Yunnan private equity transformation and development Government Leading Fund announce that the fund will focus on the technological transformation of traditional industries, technological innovation, extension industry chain, increasing product added value projects; biological resources development and deep processing projects; emerging industries and high technology. And the operation rule of the Yunnan Government Leading Fund claims the sub-fund should invest more than $70 \%$ capital in Yunnan projects. If come from market point, the LP and GP are averse to such investment restrictions. Because the principle of investment is try to find the most value project. Required a certain proportion of funds invested in the local projects. It usually leads to low efficient of usage.

\section{Suggestions}

There are several suggestions base on the situations of Government Leading Fund in China.

Firstly, improve the exit methods and procedures to make sure the operation of the fund success. In order to earning greatest benefit, the Government Leading Fund should restrict the duration and liquidation system to protect the capital operation. According to the domestic and foreign experience in venture capital, after 7 to 10 years, it will earn profits. If The Government Leading Fund exits too early or too late, it will affect the affection of investment.

Secondly, the weakening of the investment limited. The main restrict of Government Leading Fund is investment limited. If the limitations are broken, it will bring great initiative to attract high quality GP and LP.

Thirdly, raising the market contribute. Joint market capital like PE and build fund-of-fund enlarge the Government Leading fund leverage. And organize outstanding manager group. For example, Heyuan has been successfully introduced into CDB as part of their management of the Chuangyuan He FoFs(RBM 50 milliom), creating Kaiyuan FoFs (RMB 100 million). The main contribution of this two FoFs are Guochuang Yuanhe (RMB 50 milliom), Huawei Group RMB 5 billion and social security fund RMB 50 million. 


\section{Acknowledgements}

Yunnan education general project, project name:the development of Yunnan Government Leading Fund work with private equity the project number:2013Y083

\section{References}

[1] Junwu Huang, Government Leading Fund support the strategies new industry. New material industry, 2012(3): 71- 75

[2] Zhaohui Lee. Establish national strategies new industry Leading Fund of VC. Discuss mordent economy10(2011): 39- 43

[3] Xia Qian. Analyzes Leading Fund support the new industry. economy system innovation , 5(2011): 130- 133

[4] Liming Wang \& Jilin Wang. The research in situation, problems and suggestions about domestice Leading Fund.Modern management society, 2 (2010): 112- 114

[5] Dakai Yang \& Dandan Lee. The research of the affections between Government Leading Fund and private equity. Modern management society, 4(2012): 24- 26

[6] The research about Government Leading Fund in China, Zhongtou research centre. small and medium business finance, 7(2015): 10- 13 